\title{
Low incidence of maxillary hypoplasia in isolated cleft palate
}

\author{
Vitali Azouz ${ }^{*^{*}}$, Marilyn $\mathrm{Ng}^{2}$, Niyant Patel ${ }^{3}$ and Ananth S. Murthy ${ }^{3}$
}

\begin{abstract}
Background: The cause of maxillary growth restriction in patients with cleft lip and palate remains controversial. While studies have investigated the effects surgical technique and timing have on maxillary growth, few focus on patients with isolated cleft palate (ICP). The purpose of this study was to determine the impact palate repair and its associated complications may have on maxillary growth.

Methods: A retrospective chart review of ICP patients who underwent palatoplasty from 1962 to 1999 at Akron Children's Hospital was performed. Patient demographics, Veau type, age at primary repair, closure technique, presence of fistula or velopharyngeal insufficiency (VPI), number of palatal operations, maxillary hypoplasia (MH) frequency, and follow-up were recorded. Exclusion criteria included patients with cleft lip, submucous cleft, or syndromes.

Results: Twenty-nine non-syndromic ICP patients were identified; 62\% ( $n=18)$ had Veau type 1 and 38\% ( $n=11)$ had Veau type 2. All patients underwent 2-flap or Furlow palatoplasty with mobilization of mucoperiosteal flaps. Vomerine flaps were used in all Veau 2 cleft palate closures. Palatoplasty was performed at a mean age of $19.9 \pm 8.2$ months. Average follow-up was $209 \pm 66.5$ months. The rate of VPI was 59\% $(n=17)$ and the rate of oronasal fistula was $14 \%$ $(n=4)$.

Conclusions: There was a low incidence of $\mathrm{MH}$ despite complications after initial palate closure. Our results seem to suggest that age at palate closure, type of cleft palate, and type of surgical technique may not be associated with $\mathrm{MH}$. Additionally, subsequent procedures and complications after primary palatoplasty such as VPI and palatal fistula may not restrict maxillary growth.
\end{abstract}

Keywords: Cleft lip and palate, Maxillary growth, Isolated cleft palate, Complications, Velopharyngeal insufficiency, Palatal fistula

\section{Introduction}

The cause of maxillary growth restriction in patients with cleft lip and palate (CLP) remains controversial. Some authors suggest that the intrinsic primary anomaly leads to maxillary hypoplasia (MH) [1-3]. Other authors believe that palatoplasty contributes to this phenomenon as numerous reports have noted normal maxillary growth in nonoperative CLP patients [4-9]. This has led to numerous studies that investigated the effects of surgical technique and timing have on maxillary growth.

\footnotetext{
* Correspondence: Vazouz@gmail.com

${ }^{1}$ Department of Surgery, Summa Health System, 55Arch Street, Suite 2F, Akron, $\mathrm{OH}$ 44304-1423, USA

Full list of author information is available at the end of the article
}

Interestingly, patients who underwent lip repair for cleft lip alone had similar maxillary retrusion rates to CLP patients that underwent lip and palate repair $[8,9]$ suggesting that lip repair and not palate repair may case growth restriction $[8,10,11]$.

Currently, few studies focus on isolated cleft palate (ICP) patients [2, 12-15]. The purpose of this study was to determine the impact palate repair and its associated complications may have on maxillary growth.

\section{Methods}

After obtaining institutional review board approval, a retrospective chart review of non-syndromic, ICP patients who underwent palatoplasty from 1962 to 1999 at 
Akron Children's Hospital was performed. Patient demographics, Veau type, age at primary cleft palate repair, repair technique, presence of fistula or velopharyngeal insufficiency (VPI), age at VPI correction, total number of palatal operations, $\mathrm{MH}$ frequency, and length of follow-up were recorded for each patient. Patients were determined to have velopharyngeal insufficiency based on perceptual speech evaluation performed by a certified speech and language pathologist. $\mathrm{MH}$ was defined as any patient that required maxillary advancement and/or whose occlusion could not be corrected orthodontically. A minimum follow-up of 12 years was used to determine maxillary position. Exclusion criteria included patients with cleft lip, syndromic patients, patients with a submucous cleft, patients who had corrective surgery after 4 years of age, and patients whose age at follow-up was less than 12 years.

Subgroup analysis was performed to determine the relation of age groups to $\mathrm{MH}$. Age group 1 included patients less than 12 months. Age group 2 included patients from 12.1 to 18 months. Age group 3 included patients from 18.1 to 24 months. Age group 4 included patients from 24 to 48 months.

Categorical variables are presented as actual incidence. Continuous variables are presented as means with standard deviations. Categorical variables were examined using the chi-square or Fisher's exact test as appropriate. Continuous variables were examined using a student's $t$ test. Statistical significance was set at $p<0.05$. Incomplete charts were excluded from our analysis. Microsoft Excel (Microsoft Corp., Redmond, WA, USA) was used for all analyses.

\section{Results}

Our retrospective review identified 189 patients. After applying our exclusion criteria, 29 non-syndromic ICP patients that underwent surgical repair by 8 surgeons were identified (Fig. 1); 14 patients (48\%) were males and 15 patients $(52 \%)$ were female. Using the Veau classification, $62 \%(n=18)$ had Veau type 1 cleft palate and $38 \%(n=11)$ had Veau type 2. Mucoperiosteal (Veau) flaps were raised in all palate closures, and vomerine flaps were used in all Veau type 2 cleft palate closure. Palatoplasty was performed at a mean age of $19.9 \pm$ 8.2 months (Table 1). Patients were followed for an average of $209 \pm 66.5$ months and all patients were older than 12 at follow-up.

The rate of VPI was $59 \%(n=17)$ and the rate of oronasal fistula was $14 \%(n=4)$. Fourteen patients required secondary speech surgery and underwent surgery at a mean age of $147.1 \pm 91.2$ months (Table 1). Of these patients, $79 \%(n=11)$ underwent a pharyngeal flap and 7\% $(n=3)$ underwent pharyngoplasty. Half of the patients that developed an oronasal fistula had corrective surgery.
Subgroup analysis failed to reach statistical significance. Patients in group 2 had the highest incidence of VPI and complications. The only case of $\mathrm{MH}$ occurred in group 3 (Table 2). This one patient (2\%), who underwent palate closure at 14 months, developed maxillary hypoplasia requiring LeFort I advancement at 16 years. The patient subsequently developed VPI requiring corrective surgery at 17.3 years.

\section{Discussion}

Since noted by Graber [16], the cause of maxillary growth in CLP patients remains controversial to this day. In our study, we exclusively reviewed ICP patients with Veau types 1 and 2 that underwent surgical repair in our study to determine factors associated with $\mathrm{MH}$. Though the low incidence of $\mathrm{MH}$ in our study is similar to that found in the literature $[14,17,18]$, our small sample size prevented statistical analysis. However, our results seem to suggest that the age of initial palatal closure and palatoplasty technique are not associated with maxillary growth restriction. Multiple surgeons were involved in our study, and in spite of varied techniques, and differing results in terms of fistula and VPI, the variability did not seem to contribute to maxillary growth in ICP.

Numerous studies have shown the adverse effects of scarring after palatoplasty $[5-7,9]$ and cheiloplasty have on maxillary growth $[8,10,11]$. In our study, we only evaluated ICP patients to isolate the potential effect that palate repair may have on maxillary growth. Only one patient in our cohort developed $\mathrm{MH}$ despite a high rate of postoperative complications including VPI and oronasal fistula. This seems to suggest that postoperative complications and the cumulative number of subsequent surgical procedures that address these complications do not contribute to maxillary growth restriction. This may imply that scaring from the initial palatoplasty and subsequent procedures does not affect maxillary growth restriction. Although many authors have focused on the relationship between surgical technique of the initial palatoplasty and maxillary growth [19-23], we believe technical nuances such as raising mucoperiosteal flaps or vomerine flaps may not alter the maxillary growth trajectory. Patient age at the time of repair also did not seem to have an effect either. Our average age at initial palatoplasty exceeded that of the patient requiring $\mathrm{MH}$ (19 vs. 14 months). These observations are similar to that of Odom et al. who also noted that timing and techniques for palatal repair do not have a deleterious effect on antero-posterior maxillary growth [14].

The high rate of secondary procedures we observed in our cohort despite a low incidence of $\mathrm{MH}$ is also noteworthy. Interestingly, a higher rate of secondary procedures has been reported after cleft palate closure in 


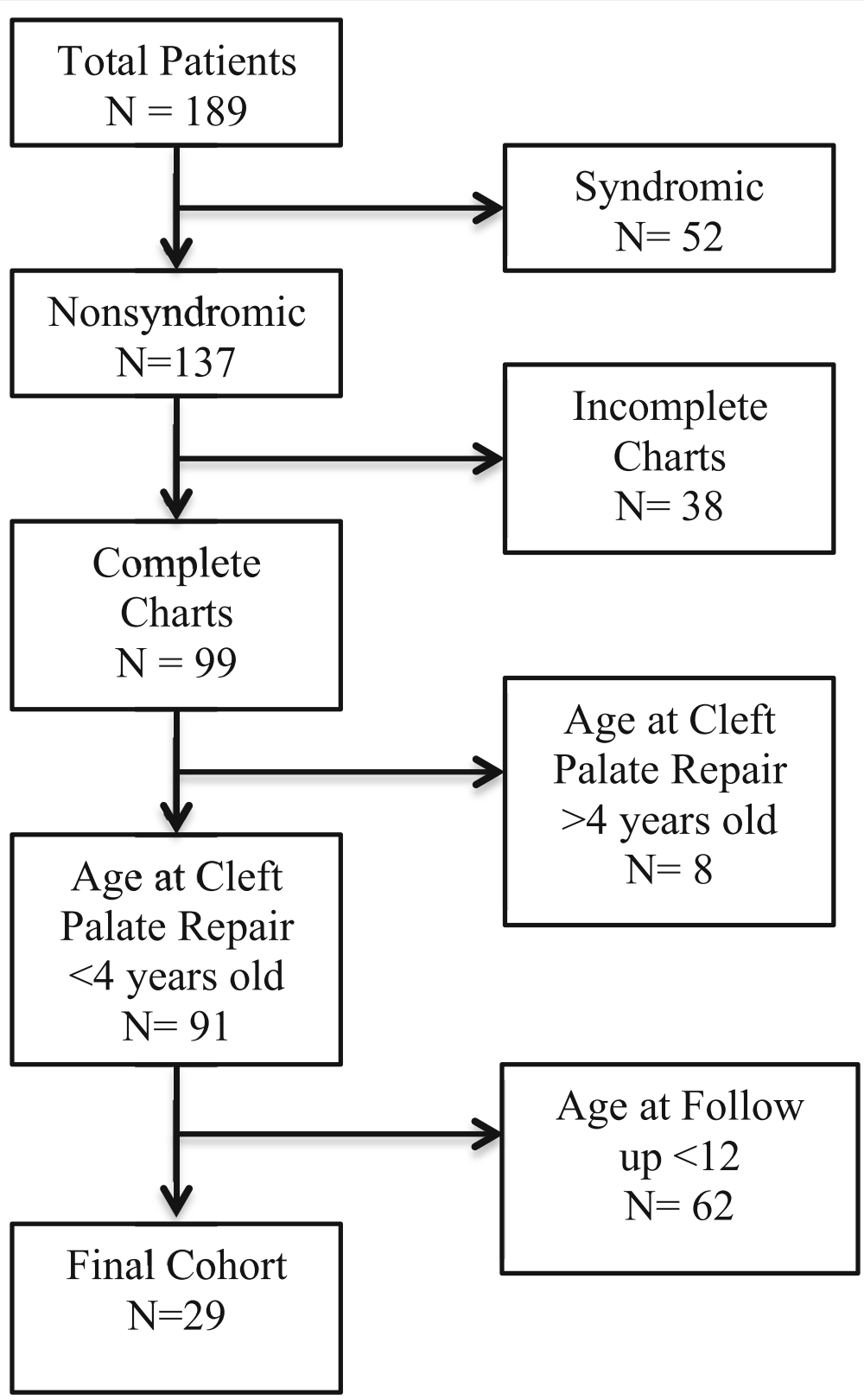

Fig. 1 Flow diagram of chart review

patients with ICP. As Chorney et al. noted in their case series of 312 patients, patients with Veau type 2 have a statistically higher rate of pharyngeal flap requirement and oronasal fistula repair [21]. Similarly, in their study

Table 1 Age and time of surgery (months)

\begin{tabular}{llll}
\hline & Mean & Standard deviation & N \\
\hline Age at CP repair & 19.8 & 8.2 & 29 \\
Age at VPI surgery & 147.1 & 91.2 & 13 \\
Time from CP to VPI surgery & 88.8 & 61.8 & 9 \\
\hline
\end{tabular}

VPI velopharyngeal insufficiency, $C P$ cleft palate of 869 non-syndromic cleft palate patients, Jackson et al. found that patients with ICP had the worst speech outcomes and higher rates of secondary surgery for

Table 2 Subgroup analysis by age

\begin{tabular}{lllll}
\hline Age group (months) & Number of patients & MH & Fistula & VPI \\
\hline Group $\mathbf{1}<\mathbf{1 2}$ & 4 & 0 & 2 & 3 \\
Group $\mathbf{2}>\mathbf{1 2 - 1 8}$ & 13 & 0 & 1 & 9 \\
Group $\mathbf{3}>\mathbf{1 8 - 2 4}$ & 6 & 1 & 1 & 3 \\
Group $\mathbf{4}>\mathbf{2 4}$ & 6 & 0 & 0 & 2 \\
\hline VPI velopharyngeal insufficiency, CP cleft palate, $M H$ maxillary hypoplasia
\end{tabular}

$V P I$ velopharyngeal insufficiency, $C P$ cleft palate, $M H$ maxillary hypoplasia 
velopharyngeal dysfunction [19]. In our cohort, four patients developed oronasal fistulas and one of these patients required two corrective procedures. This patient as well as others who had multiple corrective surgeries for complications had no evidence of maxillary growth restriction at follow-up. Seventeen patients developed VPI and 4 of these patients required at least 2 revisionary surgeries. Subgroup analysis seemed to suggest that patients whose cleft was repaired prior to 12 months were more likely to develop palatal fistulae, and overall complications where patients whose clefts were repaired between 12 and 18 months had an increased risk to develop VPI. The majority of our patients had their initial corrections performed by non-fellowship trained surgeons prior to 1980 . This may explain our high complication rate as evolving surgical techniques significantly improved outcomes after palate repair thereafter. However, in spite of our high reported VPI and fistula rate, we observed a low incidence of MH. Our results seem to suggest that age at palate closure, type of cleft palate (Veau 1 vs. 2) and type of surgical technique may not be associated with $\mathrm{MH}$. Additionally, complications after primary palatoplasty such as VPI and palatal fistula and subsequent procedures may also not restrict maxillary growth.

Due to our low incidence of $\mathrm{MH}$, our ability to deduce statically significant conclusions was limited. Additionally, our study was limited by its retrospective nature and relied on available charting. In our study, $\mathrm{MH}$ was defined by clinical judgment to perform LeFort I osteotomy and lacked quantitative lateral cephalograms that may have allowed more objective assessment and comparison to other studies. Larger prospective studies are needed to further evaluate the association of surgical technique and the rate of $\mathrm{MH}$ in the ICP patient population.

\section{Conclusions}

There was a low incidence of $\mathrm{MH}$ despite complications after initial palate closure. Our results seem to suggest that age at palate closure, type of cleft palate, and type of surgical technique may not be associated with $\mathrm{MH}$. Additionally, subsequent procedures and complications after primary palatoplasty such as VPI and palatal fistula may not restrict maxillary growth.

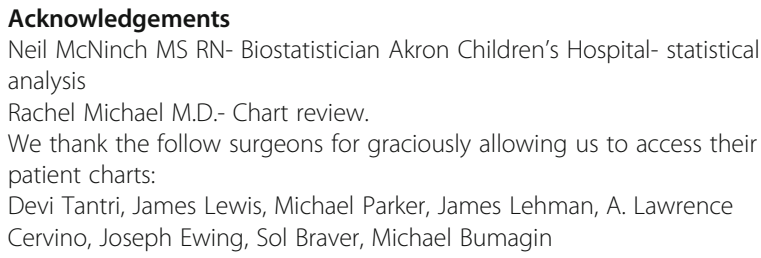

Authors' contributions

Marilyn Ng, M.D.—-study design, data entry, and data analysis. Vitali Azouz, M.D. - manuscript preparation and data analysis. Niyant Patel, M.D.—-study design, data analysis, and manuscript preparation. Ananth S. Murthy, M.D. FACS — study design, data analysis, and manuscript preparation. The authors read and approved the final manuscript.

\section{Funding}

Not Applicable. No funding was received for this study.

\section{Availability of data and materials}

Data may be made available upon request.

Ethics approval and consent to participate

Institutional Review Board (IRB) approval was granted by Akron Children's Hospital.

(IRB No: 140904)

\section{Consent for publication}

Not Applicable.

\section{Competing interests}

The authors declared that they have no competing interests.

\section{Author details}

${ }^{1}$ Department of Surgery, Summa Health System, 55Arch Street, Suite 2F, Akron, OH 44304-1423, USA. ${ }^{2}$ Plastic, Reconstructive and Hand Surgery, Northwell Health-Staten Island University Hospital, Staten Island, NY, USA. ${ }^{3}$ Plastic \& Reconstructive Surgery, Akron Children's Hospital, Akron, OH, USA.

Received: 13 February 2020 Accepted: 11 March 2020

Published online: 20 March 2020

\section{References}

1. Capelozza L, Taniguchi SM, Silva OG (1993) Craniofacial morphology of adult unoperated complete unilateral cleft lip and palate patients. Cleft Palate Craniofac J 30:376-381

2. Diah E, Lo LJ, Huang CS, Sudjatmiko G, Susanto I, Chen YR (2007) Maxillary growth of adult patients with unoperated cleft: answers to the debates. J Plast Reconstr Aesthet Surg 60:407-413

3. Iwasaki H, Kudo M, Yamamoto Y (2009) Does congenital cleft palate intrinsically influence craniofacial morphology? Craniofacial features in unoperated submucous cleft palate children in prepuberty. J Oral Maxillofac Surg 67:477-484

4. Ortiz-Monasterio F, Alfonso SR, Gustavo BP, Rodriguez-Hoffman HE, Vinageras E (1966) A study of untreated adult cleft palate patients. Plast Reconstr Surg 28:36-41

5. Ross RB (1969) The clinical implications of facial growth in cleft lip and palate. Cleft Palate J 7:37-47

6. Ross RB (1987) Treatment variables affecting facial growth in unilateral cleft lip and palate. Part 5: timing of palate repair. Cleft Palate J e24:54-63

7. Mars M, Houston WJ (1990) A preliminary study of facial growth and morphology in unoperated male unilateral cleft lip and palate subjects over 13 years of age. Cleft Palate J 27:7-10

8. Capelozza Filho L, Correa Normando AD, da Silva Filho OG (1996) Isolated influences of lip and palate surgery on facial growth: comparison of operated and unoperated male adults with UCL/P. Cleft Palate Craniofac J 33:51-56

9. Liao YF, Mars M (2005) Long-term effects of clefts on craniofacial morphology in patients with unilateral cleft lip and palate. Cleft Palate Craniofac J a 42:601-609

10. Kapucu RM, Gursu GK, Enacar A, Aras S (1996) The effect of cleft lip repair on maxillary morphology in patients with unilateral complete cleft lip and palate. Plast Reconstr Surg 97:1371-1375

11. Li Y, Shi B, Song QG, Zuo H, Zheng Q (2006) Effects of lip repair on maxillary growth and facial soft tissue development in patients with a complete unilateral cleft of lip, alveolus, and palate. J Craniomaxillofac Surg 34:355361

12. Chen ZQ, Qian YF, Wang GM, Shen G (2009) Sagittal maxillary growth in patients with unoperated isolated cleft palate. Cleft Palate Craniofac J 46: 664-667

13. Xu Y, Yang C, Schreuder WH, Shi J, Shi B, Zheng Q et al (2014) Cephalometric analysis of craniofacial morphology and growth in 
unrepaired isolated cleft palate patients. J Craniomaxillofac Surg 42:18531860

14. Odom EB, Woo AS, Mendonca DA, Huebener DV, Nissen RJ, Skolnick GB et al (2016) Long-term incisal relationships after palatoplasty in patients with isolated cleft palate. J Craniofac Surg 27:867-870

15. Elander A, Persson C, Lilja J, Mark H (2017) Isolated cleft palate requires different surgical protocols depending on cleft type. J Plast Surg Hand Surg 51:228-234

16. Graber TM (1949) Craniofacial morphology in cleft palate and cleft lip deformities. Surg Gynecol Obstet 88:359-369

17. Good PM, Mulliken JB, Padwa BL (2007) Frequency of Le Fort I osteotomy after repaired cleft lip and palate or cleft palate. Cleft Palate Craniofac J 44 396-401

18. Oberoi S, Hoffman WY, Chigurupati R, Vargervik K (2012) Frequency of surgical correction for maxillary hypoplasia in cleft lip and palate. J Craniofac Surg 23:1665-1667

19. Jackson O, Stransky CA, Jawad AF, Basta M, Solot C, Cohen M et al (2013) The Children's Hospital of Philadelphia modification of the Furlow doubleopposing Z-palatoplasty: 30-year experience and long-term speech outcomes. Plast Reconstr Surg 132:613-622

20. Timbang MR, Gharb BB, Rampazzo A, Papay F, Zins J, Doumit G (2014) A systematic review comparing Furlow double-opposing Z-plasty and straight-line intravelar veloplasty methods of cleft palate repair. Plast Reconstr Surg 134:1014-1022

21. Chorney SR, Commesso E, Tatum AS (2017) Incidence of secondary surgery after modified Furlow palatoplasty: a 20-year single-surgeon case series. Otolaryngol Head Neck Surg 157:1-6

22. Reddy RR, Reddy SG, Vaidhyanathan A, Berge SJ, Kuijpers-Jagtman AM (2017) Maxillofacial growth and speech outcome after one-stage or twostage palatoplasty in unilateral cleft lip and palate. A systematic review. J Craniomaxillofac Surg 45:995-1003

23. Rossell-Perry P, Cotrina-Rabanal O, Figallo-Hudtwalcker O, Gonzalez-Vereau A (2017) Effect of relaxing incisions on the maxillary growth after primary unilateral cleft palate repair in mild and moderate cases: a randomized clinical trial. Plast Reconstr Surg Global Open 1:1-8

\section{Publisher's Note}

Springer Nature remains neutral with regard to jurisdictional claims in published maps and institutional affiliations.

\section{Submit your manuscript to a SpringerOpen ${ }^{\circ}$ journal and benefit from:}

- Convenient online submission

- Rigorous peer review

- Open access: articles freely available online

High visibility within the field

- Retaining the copyright to your article

Submit your next manuscript at $\boldsymbol{\nabla}$ springeropen.com 